\title{
DIFFERENTIATED THYROID CARCINOMA WITH AIRWAY INVASION: INDICATION FOR TRACHEAL RESECTION BASED ON THE EXTENT OF CANCER INVASION
}

Toshirou Nishida, $\mathrm{MD}, \mathrm{PhD}^{\mathrm{a}}$

Kazuyasu Nakao, MD $^{\text {b }}$

Masayasu Hamaji, $\mathrm{MD}^{\mathrm{c}}$
Objective: Although aggressive approaches to locally invasive differentiated thyroid carcinoma are reported to improve the prognosis, few investigations have provided an indication for airway resection. The present study was undertaken to determine the best indication for airway resection for differentiated thyroid carcinoma invading the trachea. Methods: One hundred seventeen patients with differentiated thyroid carcinoma invading surrounding structures were retrospectively studied for local failures and prognosis and were divided into five groups mainly on the basis of macroscopic findings: Group 1 consisted of 40 patients who underwent tracheal resection for deep tracheal invasion; group 2 consisted of 14 patients with deep tracheal invasion and no airway resection; group 3 consisted of 13 patients with superficial tracheal invasion and no airway resection; group 4 comprised 48 patients with extrathyroidal invasion other than laryngotracheal structures; and group 5 consisted of two patients who underwent tracheal resection for superficial invasion. Results: Resectional management of the airway for patients with deep tracheal invasion decreased local recurrence and improved postoperative prognosis compared with nonresectional management for deep invasion (group 1 vs 2). Nonresectional management of the tumor, or shaving off tumor from the trachea for patients with superficial invasion, did not increase postoperative local failures or mortality (group 3 vs groups 4,5 , and 1). Conclusion: These results implied that differentiated thyroid carcinomas with superficially limited invasion could be treated successfully by nonresectional management of the trachea and that those with deep invasion should be treated by resection of the invaded trachea. (J Thorac Cardiovasc Surg 1997;114:84-92)
$\mathrm{M}$ ost differentiated thyroid carcinomas are curable after surgery. However, local invasion is accompanied by considerable postoperative morbidity and mortality, although invasion of local and regional structures is infrequent in differentiated thyroid carcinoma. ${ }^{1}$ The cause of death from differentiated thyroid carcinoma was related to local

From the First Department of Surgery, Osaka University Medical School, ${ }^{\text {a }}$ Department of Surgery, Osaka Police Hospital, ${ }^{\mathrm{b}}$ and Department of Surgery, Kure National Hospital, ${ }^{c}$ Osaka, Japan.

Received for publication Sept. 23, 1996; revisions requested Nov. 11, 1996; revisions received Feb. 20, 1997; accepted for publication Feb. 25, 1997.

Address for reprints: Toshirou Nishida, MD, PhD, First Department of Surgery, Osaka University Medical School, 2-2 Yamadaoka, Suita, Osaka 565, Japan.

Copyright (C) 1997 by Mosby-Year Book, Inc.

$0022-5223 / 97 \$ 5.00+0 \quad \mathbf{1 2 / 1 / 8 1 4 7 9}$ disease in approximately $36 \%$ to $47 \%$ of cases. ${ }^{2,3}$ Local control of invasive thyroid carcinoma, therefore, is an important clinical problem.

Aggressive approaches to locally invasive differentiated thyroid carcinoma including carcinoma with laryngotracheal invasion have been reported to improve prognosis. ${ }^{4-9}$ Despite numerous publications on this topic, unsolved problems remain in the surgical treatment of patients with laryngotracheal invasion by thyroid carcinomas. ${ }^{8}$ One of the most important problems is to determine optimal therapy for thyroid carcinoma adhering to or invading the trachea. ${ }^{9}$ Complete resection of thyroid carcinoma invading the airway has been reported to offer better survival than does incomplete resection..$^{5-8}$ However, others have recommended limited operations for locally invasive thyroid carcinoma without increasing morbidity. ${ }^{10-13}$ Thus the indication for airway resection for differentiated thyroid carcinoma 
adhering to or invading the trachea is still the subject of controversy. ${ }^{13}$ A few reports suggested the best indications for tracheal resection for differentiated thyroid carcinoma based on anatomic extension of the tumor. Shin and associates ${ }^{14}$ devised a new staging system for differentiated thyroid carcinoma involving the airway based on the extent of tracheal invasion. They reported that thyroid carcinoma expanding the tracheal mucosa is associated with a poorer prognosis than other types of invasion. ${ }^{14}$ Others claimed that superficial invasion or firm adhesion to the trachea had a better prognosis than did deep invasion. ${ }^{9}$

For more than two decades, we have aggressively treated differentiated thyroid carcinoma invading the trachea. Our indication for tracheal resection has been cancer invasion extending through the tracheal cartilage; resection was not indicated for carcinoma extending through the thyroid gland and abutting the external perichondrium. In this investigation, to establish proper indications for tracheal resection based on the extent of cancer invasion, we retrospectively compared the postoperative morbidity and mortality of patients who had locally invasive differentiated thyroid carcinoma and were treated with or without airway resection.

\section{Patients and methods}

Patient profiles. During the period from 1970 to 1994 , 301 patients with primary or recurrent differentiated thyroid cancer underwent surgery at the First Department of Surgery, Osaka University Medical School, and its affiliated hospitals, Osaka Police Hospital and Kure National Hospital. One hundred seventeen of these 301 patients had differentiated thyroid carcinoma with invasion into the surrounding tissues. Because these three hospitals are tertiary centers, locally invasive thyroid carcinoma is relatively frequent. The subjects were 33 men and 84 women, and their ages at diagnosis were $59 \pm 13$ years (mean \pm standard deviation). Ninety-six patients had primary thyroid cancer and 21 patients recurrent or secondary carcinoma. Twenty patients had no lymph node metastasis and 94 patients had various degrees of lymph node metastasis. A detailed evaluation of lymph node metastasis could not be made for three patients. Distant metastasis was evident in 15 patients at diagnosis, and 100 patients were free of distant metastasis at diagnosis. Detailed data of distant metastasis could not be obtained for two patients. One hundred eight tumors were papillary carcinomas, and nine tumors were follicular. Sixty-nine patients were alive on January 1, 1996, and 48 patients died during the follow-up period. Among these 48 patients, 30 died of thyroid cancer and 18 of unrelated causes. The mean follow-up period was 5.5 years.
Table I. Stages for differentiated thyroid carcinoma based on the extent of tracheal invasion

\begin{tabular}{|c|c|}
\hline Stages & Detailed definition \\
\hline Stage I & $\begin{array}{l}\text { Extension through the capsule of the thyroid } \\
\text { gland and abutting the external perichon- } \\
\text { drium }\end{array}$ \\
\hline Stage II & $\begin{array}{l}\text { Invasion into the cartilage or the cartilagi- } \\
\text { nous layer, or destruction of the cartilage }\end{array}$ \\
\hline Stage III & $\begin{array}{l}\text { Extension into the lamina propria of the tra- } \\
\text { cheal mucosa without epithelial invasion }\end{array}$ \\
\hline Stage IV & Invasion into or beyond the tracheal mucosa \\
\hline
\end{tabular}

This staging system is based on that detailed by Shin and colleagues. ${ }^{14}$

Operative methods. Our usual approach to thyroid cancer is macroscopically complete resection of the thyroid tumor by lobectomy plus isthmectomy or total thyroidectomy and central cervical plus ipsilateral jugular lymph node dissection when a tumor is limited to one lobe. ${ }^{15}$ Seventy-one patients underwent unilateral lobectomy plus isthmectomy and 46 underwent total or near total thyroidectomy.

Indications for surgical resections of thyroid carcinoma and operative procedures in the three hospitals were similar in principle. Tracheal invasion was preoperatively diagnosed by conventional computed tomography, bronchoscopy, echography, and recently by magnetic resonance imaging or helical computed tomography. The staging system used in the present investigation is summarized in Table I. Airway resection was indicated for patients with thyroid carcinoma, which was preoperatively or intraoperatively suspected to invade the trachea beyond the cartilage or the cartilaginous layer (stage II, III, or IV). Firm adhesion or carcinoma extending through the thyroid gland and abutting the external perichondrium of the trachea (stage I) was not treated by tracheal resection at our hospitals.

All patients routinely received thyroid-stimulating hormone suppression therapy after the operation, and no patients received prophylactic radioiodine.

Groups. One hundred seventeen patients were divided into five groups according to the presence or absence of laryngotracheal invasion and airway resection and the depth of the tracheal invasion (Table II). The 14 patients in group 2 were candidates for tracheal resection according to our criteria, but they and their families did not give informed consent for airway resection. Thus these 14 patients underwent thyroid surgery without any airway resection and had macroscopic residual cancer in the trachea. Group 3 consisted of 13 patients with stage I differentiated thyroid carcinoma and did not undergo airway resection. The tracheal edge was sharply dissected and usually ablated by electrocautery. In these cases, carcinomas extended through the thyroid gland and were histologically present at the tracheal edge of the resected tumor, but no macroscopic residual cancer was present in the trachea. Two patients who underwent tracheal resection and had been proved to have only superficial invasion in the trachea by postoperative histologic examinations were included in group 5. 
Table II. Classification of the five groups

\begin{tabular}{cllcc}
\hline $\begin{array}{c}\text { Groups } \\
(n)\end{array}$ & $\begin{array}{c}\text { Tracheal } \\
\text { invasion }\end{array}$ & \multicolumn{1}{c}{$\begin{array}{c}\text { Definition (by stage of } \\
\text { tracheal invasion) }\end{array}$} & $\begin{array}{c}\text { Method used } \\
\text { An final } \\
\text { resection }\end{array}$ & $\begin{array}{c}\text { Yecision-making } \\
\text { des }\end{array}$ \\
\hline Group 1 (40) & Deep & Stage II, III, or IV & Histologic \\
Group 2 (14) & Deep & Stage II, III, or IV & No & Macroscopic \\
Group 3 (13) & Superficial & Stage I & No & Macroscopic \\
Group 4 (48) & No invasion & Invasion into surrounding tissues other than the airway & No & Histologic \\
Group 5 (2) & Superficial & Stage I & Yes & Histologic \\
\hline
\end{tabular}

Table III. Demographics of patients with deep tracheal invasion of differentiated thyroid carcinoma

\begin{tabular}{|c|c|c|c|c|c|c|c|}
\hline & \multicolumn{3}{|c|}{ Group I $(n=40)$} & \multicolumn{3}{|c|}{ Group $2(n=14)$} & \multirow[b]{2}{*}{$p$ Value } \\
\hline & No. & $\%$ & $95 \% C I$ & No. & $\%$ & $95 \% C I$ & \\
\hline Age (yr) & $60 \pm 12$ & & $58.1-61.9$ & $67 \pm 13$ & & $63.5-70.5$ & 0.0524 \\
\hline Sex & & & & & & & 0.5457 \\
\hline Male & 18 & $45 \%$ & $29 \%-61 \%$ & 4 & $29 \%$ & $4 \%-53 \%$ & \\
\hline Female & 22 & $55 \%$ & $39 \%-71 \%$ & 10 & $71 \%$ & $47 \%-96 \%$ & \\
\hline Tumor & & & & & & & 0.0828 \\
\hline Primary & 27 & $68 \%$ & $53 \%-82 \%$ & 13 & $93 \%$ & $79 \%-107 \%$ & \\
\hline Secondary & 13 & $32 \%$ & $18 \%-47 \%$ & 1 & $7 \%$ & $-7 \%-21 \%$ & \\
\hline Lymph node metastasis at diagnosis & & & & & & & 0.3190 \\
\hline Negative & 6 & $15 \%$ & $4 \%-26 \%$ & 0 & $0 \%$ & $0 \%-0 \%$ & \\
\hline Positive & 34 & $85 \%$ & $74 \%-96 \%$ & 11 & $79 \%$ & $56 \%-101 \%$ & \\
\hline Unknown & 0 & $0 \%$ & $0 \%-0 \%$ & 3 & $21 \%$ & $-1 \%-44 \%$ & \\
\hline Distant metastasis at diagnosis & & & & & & & 0.2125 \\
\hline Absent & 34 & $85 \%$ & $74 \%-96 \%$ & 8 & $57 \%$ & $30 \%-84 \%$ & \\
\hline Present & 6 & $15 \%$ & $4 \%-26 \%$ & 4 & $29 \%$ & $4 \%-53 \%$ & \\
\hline Unknown & 0 & $0 \%$ & $0 \%-0 \%$ & 2 & $14 \%$ & $-4 \%-33 \%$ & \\
\hline Method & & & & & & & 0.2182 \\
\hline Lobectomy & 17 & $43 \%$ & $27 \%-58 \%$ & 9 & $64 \%$ & $38 \%-90 \%$ & \\
\hline Total & 23 & $57 \%$ & $42 \%-73 \%$ & 5 & $36 \%$ & $10 \%-62 \%$ & \\
\hline Histology & & & & & & & 0.0334 \\
\hline Papillary & 38 & $95 \%$ & $88 \%-102 \%$ & 10 & $71 \%$ & $47 \%-96 \%$ & \\
\hline Follicular & 2 & $5 \%$ & $-2 \%-12 \%$ & 4 & $29 \%$ & $4 \%-53 \%$ & \\
\hline \multicolumn{8}{|l|}{ Invasion* } \\
\hline Jugular vein & $19 / 40$ & $48 \%$ & $32 \%-63 \%$ & $4 / 14$ & $29 \%$ & $4 \%-53 \%$ & 0.3470 \\
\hline Carotid artery & $2 / 40$ & $5 \%$ & $-2 \%-12 \%$ & $4 / 14$ & $29 \%$ & $4 \%-53 \%$ & 0.0334 \\
\hline Anterior cervical muscles & $28 / 40$ & $70 \%$ & $56 \%-84 \%$ & $11 / 14$ & $79 \%$ & $56 \%-101 \%$ & 0.7326 \\
\hline Sternocleidmastoid muscle & $7 / 40$ & $18 \%$ & $6 \%-29 \%$ & $3 / 14$ & $21 \%$ & $-1 \%-44 \%$ & 1.000 \\
\hline Recurrent laryngeal nerve & $29 / 40$ & $73 \%$ & $58 \%-87 \%$ & $10 / 12$ & $83 \%$ & $61 \%-105 \%$ & 0.7063 \\
\hline Phrenic nerve & $2 / 40$ & $5 \%$ & $-2 \%-12 \%$ & $3 / 14$ & $21 \%$ & $-1 \%-44 \%$ & 0.1031 \\
\hline Vagus nerve & $7 / 40$ & $18 \%$ & $6 \%-29 \%$ & $1 / 12$ & $8 \%$ & $-8 \%-25 \%$ & 0.6634 \\
\hline Accessory nerve & $3 / 40$ & $8 \%$ & $-1 \%-16 \%$ & $0 / 14$ & $0 \%$ & $0 \%-0 \%$ & 0.5597 \\
\hline Esophagus & $16 / 40$ & $40 \%$ & $25 \%-55 \%$ & $10 / 12$ & $83 \%$ & $61 \%-105 \%$ & 0.0188 \\
\hline
\end{tabular}

"Invasion into surrounding structures was determined by intraoperative findings in the present investigation. The number of patients with invasion/the number of total patients for whom detailed data were available is shown.

Statistical analysis. Fisher's exact test, the $\chi^{2}$ test for nonparametric variables, and Student's $t$ test for parametric variables were used for analysis. The Kaplan-Meier method for postoperative survival with the log rank test was used for statistical comparisons. The relative importance of various prognostic factors for postoperative sur- vival as identified by multivariable analysis was analyzed with Cox's proportional hazards model with the forward stepwise method. ${ }^{16}$ Assumptions of proportional hazards had been tested. All statistical analyses were performed with the use of a commercially available personal computer program (SPSS, Inc., Chicago, Ill.). 
Table IV. Postoperative recurrence rates and prognoses of patients with deep tracheal invasion of differentiated thyroid carcinoma

\begin{tabular}{|c|c|c|c|c|c|c|c|}
\hline & \multicolumn{3}{|c|}{ Group $1(n=40)$} & \multicolumn{3}{|c|}{ Group $2(n=14)$} & \multirow[b]{2}{*}{$p$ Value } \\
\hline & No. & $\%$ & $95 \% C I$ & No. & $\%$ & $95 \% \mathrm{CI}$ & \\
\hline \multicolumn{8}{|l|}{ Recurrence** } \\
\hline Total & $17 / 40$ & $43 \%$ & $27 \%-58 \%$ & $11 / 14$ & $79 \%$ & $56 \%-101 \%$ & 0.0296 \\
\hline Local $\dagger$ & $3 / 40$ & $8 \%$ & $-1 \%-16 \%$ & $11 / 14$ & $79 \%$ & $56 \%-101 \%$ & $<0.0001$ \\
\hline Lymph node & $11 / 40$ & $28 \%$ & $13 \%-41 \%$ & $5 / 12$ & $42 \%$ & $13 \%-71 \%$ & 0.5656 \\
\hline Distant & $13 / 40$ & $33 \%$ & $18 \%-47 \%$ & $3 / 12$ & $25 \%$ & $-1 \%-51 \%$ & 0.7331 \\
\hline Overall prognosis & & & & & & & 0.0535 \\
\hline Alive & 19 & $48 \%$ & $33 \%-62 \%$ & 2 & $14 \%$ & $7 \%-22 \%$ & \\
\hline Dead & 21 & $52 \%$ & $36 \%-69 \%$ & 12 & $86 \%$ & $39 \%-132 \%$ & \\
\hline
\end{tabular}

*The number of patients with recurrence/the number of total patients for whom detailed data were available is shown.

$\dagger$ In group 2, local recurrence was defined as newly developed carcinoma other than at tracheal edge or progress of residual carcinoma.

\section{Results}

Deep tracheal invasion. To evaluate the effect of aggressive surgery on differentiated thyroid carcinoma with deep invasion in the trachea, we compared prognosis and postoperative recurrence in groups 1 and 2. The demographics of the two groups indicated that patients in group 2 were relatively older and had tumors that were predominantly follicular (Table III). Macroscopic invasion into the carotid artery and the esophagus was common in group 2, which suggests that patients in group 2 might have had more advanced thyroid carcinoma than those in group 1. After a mean follow-up period of 1.2 years, 11 of 14 patients in group 2 suffered from local recurrence. Two patients were alive with distant metastasis and no newly developed local recurrences, although their follow-up periods were short. In contrast to group 2, only three patients in group 1 had local recurrences, whereas 17 patients had all types of recurrences during the mean follow-up period of 6.1 years. The local recurrences and the number of patients with any recurrences were decreased in group 1 compared with group 2 (Table IV).

Eleven patients in group 2 died of the cancer mainly as a result of local recurrence, one died during hospitalization, and two patients were alive with distant metastasis on January 1, 1996. Seventeen patients in group 1 were alive without metastasis, two were alive with distant metastasis, and 21 patients died during the follow-up period, including nine who died of the cancer and 12 who died of unrelated causes (Table IV). The prognosis of group 1 was better than that of group 2. Mean overall survival of group 1 ( $8.7 \pm 1.1$ years) was statistically better than that of group 2 (1.5 \pm 0.4 years) (Fig. 1, $p<0.0001)$. The importance of tracheal resection for these patients with deep tracheal invasion was further confirmed by Cox's proportional hazards model. With the use of data obtained from patients in groups 1 and 2, multivariable analysis was performed with possible prognostic factors such as age, sex, primary or secondary operation, lymph node metastasis, distant metastasis at diagnosis (no $=0$ and yes $=1$ ), operative method, resectional management of the airway (no $=0$ and yes $=1$ ), histologic characteristics, and invasion into the esophagus, carotid artery, jugular vein, anterior cervical muscle, sternocleidomastoid muscle, recurrent laryngeal nerve, phrenic nerve, vagal nerve, and accessory nerve. The data suggested that resectional management of the airway $(p=0.0004)$ and distant metastasis at diagnosis $(p=0.0170)$ were independent prognostic factors with relative risks of 0.192 (95\% confidence intervals $[\mathrm{CI}]=0.121$ to 0.304 ) and $2.868(95 \% \mathrm{CI}=1.844$ to 4.464$)$, respectively. The other factors examined were not independent prognostic factors. The importance of tracheal resection for patients with deep tracheal invasion was also confirmed with the use of the data obtained from 117 patients. Cox's proportional hazards model with the forward stepwise method indicated that esophageal invasion (no $=0$ and yes $=1, p=$ 0.0028 ), invasion into the sternocleidomastoid muscle (no $=0$ and yes $=1, p=0.0085$ ), and group 2 $(p<0.0001)$ were independent prognostic factors for overall survival with a relative risk of 2.713 (95\% $\mathrm{CI}=2.113$ to 3.483$), 2.750(95 \% \mathrm{CI}=1.917$ to 3.861 ), and 6.414 (95\% CI $=4.362$ to 9.422), respectively. The other factors and the other groups were not prognostic for differentiated thyroid carcinoma with extrathyroidal invasion.

Superficial tracheal invasion. In the second series of the present investigation, nonresectional management for superficial tracheal invasion, was 


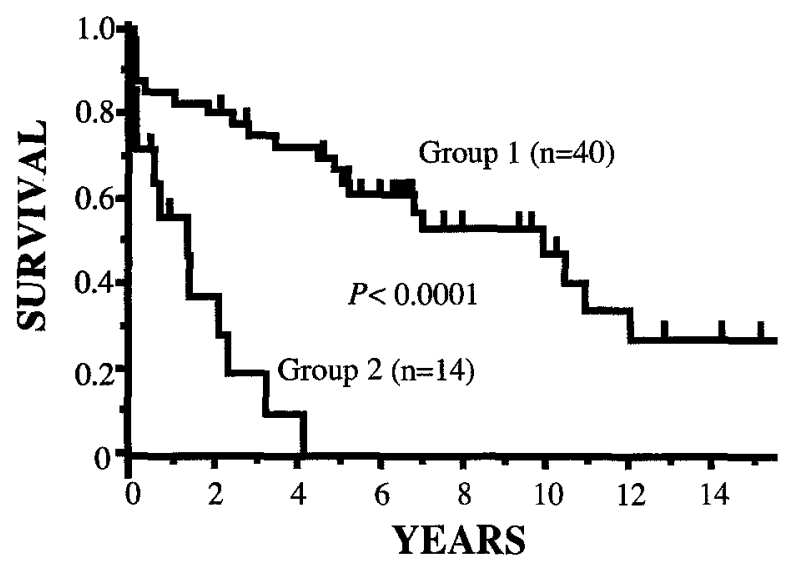

Fig. 1. Postoperative overall survival of groups 1 and 2 . Postoperative overall survival was compared between group $1(n=40)$ and group $2(n=14)$ by means of the Kaplan-Meier method. Mean postoperative survival of group $1(8.7 \pm 1.1$ years $)$ was better than that of group 2 $(1.5 \pm 0.4$ years $)(p<0.0001)$

verified by comparison of postoperative recurrence, as well as the prognosis between groups 3 and 1 or between groups 3 and 4 (or group 5).

The demographics of groups 3 and 4 were similar (Table V). Even when group 5 was added in this comparison, most factors examined were similar. Postoperative recurrence was compared between group 3 and group 4, and rates of total, local, regional, and distant metastatic recurrences were not different between the two groups (Table VI) after mean follow-up periods of 7.2 and 5.7 years for group 3 and group 4, respectively. Local recurrence was similar among groups 3, 4, and 5, even after nonresectional management for patients with suspected or superficial invasion of differentiated thyroid carcinoma.

Nine of 13 patients in group 3 were alive without recurrence on January 1, 1996, three had died of the cancer, and one had died of operative complications. In group 4, 36 patients were alive without recurrence and two patients were alive with recurrence. Nine patients had died of the cancer and one had died of an unrelated cause. In group 5, one patient was alive without recurrence on January 1, 1996, and the other had died of cancer. The postoperative prognoses among the three groups were similar (see Table VI). Mean overall survival periods of groups 3,4 , and 5 were $12.9 \pm 2.2,11.9 \pm 1.1$ (mean \pm standard deviation), and 10.3 (mean) years, respectively. Postoperative survival was similar between groups 3 and 4 (Fig. 2). The importance

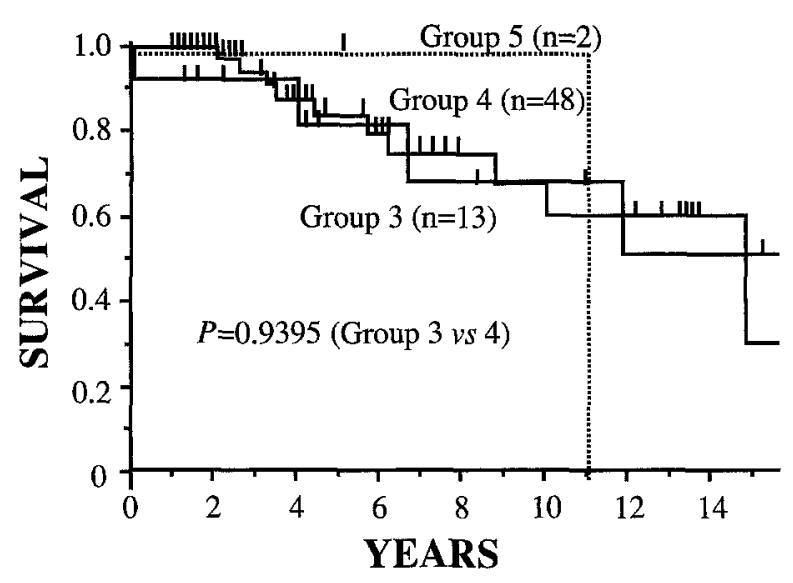

Fig. 2. Postoperative overall survival of groups 3, 4, and 5. Postoperative overall survival was compared between group $3(n=13)$ and group $4(n=48)$ by means of the Kaplan-Meier method. No statistically significant differences were noted between the two groups $(p=0.9395)$. The dotted line indicates survival of group 5. Postoperative survivals of the three groups were similar.

of several prognostic factors was further examined with data obtained from 63 patients in groups 3, 4, and 5 with the use of Cox's proportional hazards model. However, no independent prognostic factor was indicated in these settings.

No statistically significant differences were detected in local, regional, distant, or total recurrences of the cancer between group 3 and group 1 (data not shown). The mean postoperative survival period of group $3(12.9 \pm 2.2$ years) was not different from that of group $1(8.7 \pm 1.1$ years, $p=0.3935)$. These results suggested that nonresectional management of the trachea for superficial tracheal invasion did not increase postoperative morbidity or mortality.

\section{Discussion}

Invasion of the trachea by thyroid carcinoma is the main cause of death in patients who die of differentiated thyroid carcinoma. The best management is en bloc surgical resection of the tumor invading the trachea.-9, 17 Surgical treatment of thyroid carcinoma invading the trachea is still a challenging problem for surgeons treating endocrine disorders. However, faced with thyroid carcinoma invading the trachea, the surgeon may hesitate between conservative resection or a more radical approach because most differentiated thyroid carcinomas have a favorable prognosis and postoperative morbidity is an important consideration for these patients. ${ }^{9}$ For differentiated thyroid carcinoma with 
Table V. Demographics of patients with differentiated thyroid carcinoma with superficial tracheal invasion or without tracheal invasion

\begin{tabular}{|c|c|c|c|c|c|c|c|c|c|c|c|}
\hline & \multicolumn{3}{|c|}{ Group $3(n=13)$} & \multicolumn{3}{|c|}{ Group $4(n=48)$} & \multicolumn{3}{|c|}{ Group $5(n=2)$} & \multicolumn{2}{|c|}{$p$ Value } \\
\hline & No. & $\%$ & $95 \% C I$ & No. & $\%$ & $95 \% C I$ & No. & $\%$ & $95 \% C I$ & Two groups & (Three groups) \\
\hline Age (yr) & $60 \pm 10$ & & $57.2-62.8$ & $55 \pm 14$ & & $53.0 \pm 57.0$ & 65 & & & 0.2473 & $(0.4355)$ \\
\hline \multicolumn{12}{|l|}{ Sex } \\
\hline Male & 1 & $8 \%$ & $-7 \%-23 \%$ & 10 & $21 \%$ & $9 \%-32 \%$ & 0 & $0 \%$ & $0 \%-0 \%$ & 0.4290 & $(0.4355)$ \\
\hline Female & 12 & $92 \%$ & $77 \%-107 \%$ & 38 & $79 \%$ & $68 \%-91 \%$ & 2 & $100 \%$ & $100 \%-100 \%$ & & \\
\hline \multicolumn{12}{|l|}{ Tumor } \\
\hline Primary & 11 & $85 \%$ & $64 \%-105 \%$ & 43 & $90 \%$ & $81 \%-98 \%$ & 2 & $100 \%$ & $100 \%-100 \%$ & 0.6181 & $(0.5140)$ \\
\hline Secondary & 2 & $15 \%$ & $-5 \%-36 \%$ & 5 & $10 \%$ & $2 \%-19 \%$ & 0 & $0 \%$ & $0 \%-0 \%$ & & \\
\hline $\begin{array}{l}\text { Lymph node metastasis } \\
\text { at diagnosis }\end{array}$ & & & & & & & & & & 1.0000 & $(0.7444)$ \\
\hline Negative & 3 & $23 \%$ & $-1 \%-47 \%$ & 11 & $23 \%$ & $11 \%-35 \%$ & 0 & $0 \%$ & $0 \%-0 \%$ & & \\
\hline Positive & 10 & $77 \%$ & $53 \%-101 \%$ & 37 & $77 \%$ & $65 \%-89 \%$ & 2 & $100 \%$ & $100 \%-100 \%$ & & \\
\hline $\begin{array}{l}\text { Distant metastasis } \\
\text { at diagnosis }\end{array}$ & & & & & & & & & & 0.1963 & $(0.0340)$ \\
\hline Absent & 11 & $85 \%$ & $64 \%-105 \%$ & 46 & $96 \%$ & $90 \%-102 \%$ & 1 & $50 \%$ & $-48 \%-148 \%$ & & \\
\hline Present & 2 & $15 \%$ & $-5 \%-36 \%$ & 2 & $4 \%$ & $-2 \%-10 \%$ & 1 & $50 \%$ & $-48 \%-148 \%$ & & \\
\hline Method & & & & & & & & & & 0.2577 & $(0.4218)$ \\
\hline Lobectomy & 11 & $85 \%$ & $64 \%-105 \%$ & 33 & $69 \%$ & $56 \%-82 \%$ & 1 & $50 \%$ & $-48 \%-148 \%$ & & \\
\hline Total & 2 & $15 \%$ & $-5 \%-36 \%$ & 15 & $31 \%$ & $18 \%-45 \%$ & 1 & $50 \%$ & $-48 \%-148 \%$ & & \\
\hline Histology & & & & & & & & & & $>0.9999$ & $(0.8259)$ \\
\hline Papillary & 12 & $92 \%$ & $75 \%-108 \%$ & 46 & $96 \%$ & $90 \%-102 \%$ & 2 & $100 \%$ & $100 \%-100 \%$ & & \\
\hline Follicular & 1 & $8 \%$ & $-8 \%-25 \%$ & 2 & $4 \%$ & $-2 \%-10 \%$ & 0 & $0 \%$ & $0 \%-0 \%$ & & \\
\hline \multicolumn{12}{|l|}{ Invasion $\dagger$} \\
\hline Trachea & $13 / 13$ & $100 \%$ & $100 \%-100 \%$ & $0 / 48$ & $0 \%$ & $0 \%-0 \%$ & $2 / 2$ & $100 \%$ & $100 \%-100 \%$ & $<0.0001$ & $(<0.0001)$ \\
\hline Jugular vein & $3 / 13$ & $23 \%$ & $-1 \%-47 \%$ & $17 / 48$ & $35 \%$ & $22 \%-49 \%$ & $1 / 2$ & $50 \%$ & $-48 \%-148 \%$ & 0.5159 & $(0.6191)$ \\
\hline Carotid artery & $0 / 13$ & $0 \%$ & $0 \%-0 \%$ & $1 / 48$ & $2 \%$ & $-2 \%-6 \%$ & $1 / 2$ & $50 \%$ & $-48 \%-148 \%$ & 1.0000 & $(0.0006)$ \\
\hline $\begin{array}{l}\text { Anterior cervical } \\
\text { muscle }\end{array}$ & & & & & & & & & & 1.0000 & (0.7661) \\
\hline & $4 / 13$ & $31 \%$ & $5 \%-57 \%$ & $13 / 48$ & $27 \%$ & $14 \%-40 \%$ & $1 / 2$ & $50 \%$ & $-48 \%-148 \%$ & & \\
\hline $\begin{array}{l}\text { Sternocleidmastoid } \\
\text { muscle }\end{array}$ & & & & & & & & & & 1.0000 & $(0.6113)$ \\
\hline & $0 / 13$ & $0 \%$ & $0 \%-0 \%$ & $3 / 48$ & $6 \%$ & $-1 \%-13 \%$ & $0 / 2$ & $0 \%$ & $0 \%-0 \%$ & & \\
\hline \multirow[t]{2}{*}{$\begin{array}{l}\text { Recurrent laryngeal } \\
\text { nerve }\end{array}$} & & & & & & & & & & 0.3474 & $(0.1504)$ \\
\hline & $4 / 13$ & $31 \%$ & $5 \%-57 \%$ & $24 / 48$ & $50 \%$ & $36 \%-64 \%$ & $2 / 2$ & $100 \%$ & $100 \%-100 \%$ & & \\
\hline Phrenic nerve & $0 / 13$ & $0 \%$ & $0 \%-0 \%$ & $1 / 48$ & $2 \%$ & $-2 \%-6 \%$ & $0 / 2$ & $0 \%$ & $0 \%-0 \%$ & 1.0000 & $(0.8532)$ \\
\hline Vagus nerve & $1 / 13$ & $8 \%$ & $-7 \%-23 \%$ & $0 / 48$ & $0 \%$ & $0 \%-0 \%$ & $0 / 2$ & $0 \%$ & $0 \%-0 \%$ & 1.0000 & (0.1417) \\
\hline \multirow[t]{2}{*}{ Accessory nerve } & & & & & & & & & & 1.0000 & $(0.8532)$ \\
\hline & $0 / 13$ & $0 \%$ & $0 \%-0 \%$ & $1 / 48$ & $2 \%$ & $-2 \%-6 \%$ & $0 / 2$ & $0 \%$ & $0 \%-0 \%$ & & \\
\hline Esophagus & $2 / 13$ & $15 \%$ & $-5 \%-36 \%$ & $8 / 48$ & $17 \%$ & $6 \%-27 \%$ & $0 / 2$ & $0 \%$ & $0 \%-0 \%$ & 1.0000 & $(0.8178)$ \\
\hline
\end{tabular}

*The $p$ values indicated are those between group 3 and group $4 ; p$ values in parentheses are those among the three groups.

$\dagger$ Invasion into surrounding structures was determined by intraoperative findings in the present investigation. The number of patients with invasion/the number of total patients for whom detailed data were available is shown.

extrathyroidal extension, complete resection of the tumor has been reported to offer a better chance for survival than incomplete resection. ${ }^{1,5,6,18,19}$ Many authors have advocated complete surgical resection for invasive thyroid carcinoma with airway resection. ${ }^{1,5,6,18}$ However, operative morbidity with resectional management of the trachea may be similar to that without tracheal resection. ${ }^{7,10,12,17}$ Surgeons may shave off the neoplastic tissue with electrocautery, cut into the tracheal ring, or resect the trachea when faced with differentiated thyroid carcinoma with firm adhesion to or invasion of the trachea. The optimal indications for airway resection for invasive differentiated thyroid carcinoma have not been established.

Only a few reports have described resectional management of thyroid carcinoma invading the trachea based on anatomic considerations., 14 Shin and associates ${ }^{14}$ reported the pathologic staging of differentiated thyroid carcinoma with airway inva- 
Table VI. Postoperative recurrences and prognosis of patients with differentiated thyroid carcinoma with superficial tracheal invasion or without tracheal invasion

\begin{tabular}{|c|c|c|c|c|c|c|c|c|c|c|c|}
\hline & \multicolumn{3}{|c|}{ Group $3(n=13)$} & \multicolumn{3}{|c|}{ Group $4(n=48)$} & \multicolumn{3}{|c|}{ Group $5(n=2)$} & \multicolumn{2}{|c|}{$p$ Value } \\
\hline & No. & $\%$ & $95 \% C I$ & No. & $\%$ & $95 \% C I$ & No. & $\%$ & $95 \% C I$ & Two groups & (Three groups)* \\
\hline \multicolumn{12}{|l|}{ Recurrence $\dagger$} \\
\hline Total & $4 / 13$ & $31 \%$ & $5 \%-57 \%$ & $13 / 48$ & $27 \%$ & $14 \%-40 \%$ & $1 / 2$ & $50 \%$ & $-48 \%-148 \%$ & 1.0000 & $(0.7661)$ \\
\hline Local & $2 / 13$ & $15 \%$ & $-5 \%-36 \%$ & $6 / 48$ & $13 \%$ & $3 \%-22 \%$ & $0 / 2$ & $0 \%$ & $0 \%-0 \%$ & 1.0000 & $(0.8281)$ \\
\hline Lymph node & $5 / 12$ & $42 \%$ & $13 \%-71 \%$ & $10 / 47$ & $21 \%$ & $9 \%-33 \%$ & $1 / 2$ & $50 \%$ & $-48 \%-148 \%$ & 0.2817 & $(0.2624)$ \\
\hline Distant & $2 / 11$ & $18 \%$ & $-6 \%-42 \%$ & $7 / 47$ & $14 \%$ & $15 \%-25 \%$ & $1 / 2$ & $50 \%$ & $-48 \%-148 \%$ & 1.0000 & $(0.4222)$ \\
\hline Overall prognosis & & & & & & & & & & 0.4716 & $(0.5123)$ \\
\hline Alive & 9 & $69 \%$ & $30 \%-108 \%$ & 38 & $79 \%$ & $56 \%-102 \%$ & 1 & $50 \%$ & $-48 \%-148 \%$ & & \\
\hline Dead & 4 & $31 \%$ & $5 \%-57 \%$ & 10 & $21 \%$ & $15 \%-27 \%$ & 1 & $50 \%$ & $-48 \%-148 \%$ & & \\
\hline
\end{tabular}

*The $p$ values indicated are those between group 3 and group $4 ; p$ values in parentheses are those among the three groups.

†The number of patients with recurrence/the number of total patients for whom detailed data were available is shown.

sion. They reported that patients with stage I, II, and III tumors had diseased margins less frequently, no postoperative mortality, and good long-term survival compared with patients with stage IV tumors. They did not, however, describe local recurrences, and they made no comparisons with carcinomas with extrathyroidal invasion other than the trachea. In the present study, 2, 9, 20, and 11 patients were in stages I, II, III, and IV, respectively, when considering only those who underwent tracheal resection and had histologic examinations for tracheal invasion. No statistically significant differences in postoperative survival or recurrence were found among stages I, II, III, and IV (data not shown). McCaffrey, Bergstralh, and Hay ${ }^{1}$ reported that prognostic factors for locally invasive differentiated thyroid carcinoma were invasion of the trachea and the esophagus. When data obtained from 103 patients who underwent resectional management (patients in groups $1,3,4$, and 5 ) were analyzed by means of Cox's proportional hazards model with the forward stepwise method, distant metastasis $(p=0.0021)$, invasion in the esophagus ( $p=0.0054)$, and invasion in the sternocleidomastoid muscle $(p=0.0006)$ were independent prognostic factors with odds ratios of 4.212 (95\% CI $=2.637$ to 6.727$), 2.720$ (95\% $\mathrm{CI}=1.899$ to 3.895$)$, and $4.690(95 \% \mathrm{CI}=2.989$ to 7.359), respectively. The data obtained from the present investigation suggested that tracheal invasion was not a prognostic factor in locally invasive differentiated thyroid carcinoma after circular resection of the trachea.

When the invaded trachea is scheduled for resection, the surgeon may partially resect the invaded trachea or perform circular resection of the trachea. $^{5,6,9,13,20}$ We have routinely used circular re- section of the trachea, and only one patient, who had previously undergone circular resection and then had a local recurrence, received partial resection of the airway, reconstituted with auricular cartilage. Some investigators reported successful partial (or window) resection of the invaded trachea., 13, 21 However, other investigators advocated circular resection of the trachea because once differentiated thyroid carcinomas invade the trachea, they tend to grow along the trachea instead of actually invading the lumen. ${ }^{4-6,12}$ The problem of whether partial or circular resection is better for tracheal invasion is still under investigation. When thyroid cancer invades both sides of the larynx, in our institutions total laryngectomy is indicated. The other types of airway invasion are usually treated by airway resection and tracheotracheal or laryngotracheal anastomosis.

Melliere and coworkers ${ }^{9}$ reported that thyroid carcinomas with firm adhesions to or superficial invasion of the trachea (stage I) had a better prognosis than those with deep invasion. However, the thyroid carcinomas studied by them consisted of different histologic types that have a different prognosis, and their surgical approaches to these carcinomas were not always uniform. McCaffrey and Lipton $^{12}$ reported that postoperative survival of patients with complete excision was similar to that of patients with near complete excision by shaving off tumor tissue from the superficially invaded trachea. In the present investigation, differentiated thyroid carcinoma invading the trachea was uniformly treated by circular resection of the invaded trachea. The present investigation suggested that differentiated thyroid carcinomas with superficial invasion of or firm adhesions to the trachea showed similar 
postoperative recurrence and survivals after either conservative or resectional management of the trachea to those with tracheal invasion and resection, or to those with extrathyroidal invasion in nonlaryngotracheal structures.

Five-year survivals of patients with thyroid cancer invading the upper aerodigestive system were reported to be $70 \%$ to $80 \% .^{5,12,13}$ McCaffrey, Bergstralh, and Hay ${ }^{1}$ reported that 5-year and 10-year survivals of patients with locally invasive thyroid cancer were $79 \%$ and $63 \%$, respectively. Anderson and colleagues ${ }^{18}$ suggested that more than $40 \%$ of patients with locally invasive thyroid cancer had local failures during the follow-up period of 30 years, and their overall survivals at 5 and 10 years were $60 \%$ and $50 \%$, respectively. The local recurrence rate after complete resectional management for thyroid carcinomas with laryngotracheal involvement was reported to be $38 \% .^{8}$ In the present investigation, 5-year survivals of groups 1, 3, and 4 were $67 \%, 82 \%$, and $87 \%$, respectively, and local recurrence rates of the three groups were $7.5 \%$, $15.4 \%$, and $12.5 \%$, respectively. These values were comparable with those reported in thyroid carcinoma invading extrathyroidal structures including the trachea. $1,5,6,8,12,13,18,22$

Several previous reports indicated that complete resection was associated with a better prognosis than incomplete resection. ${ }^{1,5,12}$ However, $27 \%$ to $43 \%$ of patients with laryngotracheal resection for thyroid cancer were reported to have received incomplete resections to various degrees. ${ }^{5,7}$ In the present series, $11(27.5 \%)$ of 40 patients in group 1 had histologically but not macroscopically detectable residual cancer, although the residual amount of the cancer was minimized by surgery (data not shown). All patients in group 3 were believed to have residual tumors. Local recurrences and overall prognoses of these two groups were not different from previously reported values. ${ }^{1,2,5-7,12}$ Ishihara and associates ${ }^{5}$ reported that five of 18 patients with residual cancer in the tracheal edges were alive without any recurrence and that some patients survived long term despite cancer cells remaining at the stump. These results suggested that microscopic residual carcinoma cells do not always become clinically apparent after surgery and that superficially invading differentiated thyroid carcinoma could be treated without tracheal resection. Because the present investigation is retrospective and is not randomized, the final conclusion may require a large prospective randomized study for superficial invasion.

In summary, resectional management for patients with deep tracheal invasion decreased local recurrence and improved postoperative prognosis, and nonresectional management of the trachea for patients with superficial invasion did not increase postoperative local failures and mortality. These results imply that, of differentiated thyroid carcinomas invading the trachea, carcinomas with superficially limited invasion can be treated by nonresectional management of the trachea and those with deep invasion are better treated by tracheal resection. Considering postoperative morbidity, tracheal resection appears to be indicated for patients with differentiated thyroid carcinoma invading the trachea.

\section{REFERENCES}

1. McCaffrey TV, Bergstralh EJ, Hay ID. Locally invasive papillary thyroid carcinoma: 1940-1990. Head Neck 1994;16: 165-72.

2. Tollefson H, DeCosse J, Hutter R. Papillary carcinoma of the thyroid: a clinical and pathological study of 70 fatal cases. Cancer 1964:17:1035-44.

3. McCaffrey TV, Hay ID, Woolner LB, van Heerden JA, Taylor WF. Papillary thyroid cancer treated at the Mayo Clinic, 1946 through 1970: initial manifestations, pathologic findings, therapy and outcome. Mayo Clinic Proc 1986;61: 978-96.

4. Nakao K, Miyata M, Izukura M, Monden Y, Maeda M, Kawashima Y. Radical operation for thyroid carcinoma invading the trachea. Arch Surg 1984;119:1046-9.

5. Ishihara T, Kobayashi K, Kikuchi K, Kato R, Kawamura M, Ito $\mathrm{K}$. Surgical treatment of advanced thyroid carcinoma invading the trachea. J Thorac Cardiovasc Surg 1991;102: 717-20.

6. Grillo HC, Suen HC, Mathisen DJ, Wain JC. Resectional management of thyroid carcinoma invading the airway. Ann Thorac Surg 1992;54:3-9.

7. Grillo HC, Zannini P. Resectional management of airway invasion by thyroid carcinoma. Ann Thorac Surg 1986;42: 287-8.

8. Friedman M, Danielzadeh JA, Caldarelli DD. Treatment of patients with carcinoma of the thyroid invading he airway. Arch Otolaryngol Head Neck Surg 1994;120:1377-81.

9. Melliere DJM, Yahia NEB, Becquemin JP, Lange F, Boulahdour H. Thyroid carcinoma with tracheal or esophageal involvement: Limited or maximal surgery? Surgery 1993;113: 166-72.

10. Britto E, Shah S, Parikh DM, Rao RS. Laryngotracheal invasion by well-differentiated thyroid cancer: diagnosis and management. J Surg Oncol 1990;44:25-31.

11. Lawson W, Som ML, Biller HF. Papillary adenocarcinoma of the thyroid invading the upper air passages. Ann Otol Rhinol Laryngol 1977;86:751-5.

12. McCaffrey TV, Lipton RJ. Thyroid carcinoma invading the upper aerodigestive system. Laryngoscope 1990;100:824-30.

13. Ballantyne AJ. Resections of the upper aerodigestive tract for locally invasive thyroid cancer. Am J Surg 1994;168:636-9.

14. Shin D-H, Mark EJ, Suen HC, Grillo HC. Pathologic staging of papillary carcinoma of the thyroid with airway invasion based on the anatomic manner of extension to the trachea: a clinicopath- 
ologic study based on 22 patients who underwent thyroidectomy and airway resection. Hum Pathol 1993;24:866-970.

15. Nishida $T$, Nakao $K$, Hamaji $M$, Nakahara $M$, Tsujimoto $M$. Overexpression of $\mathrm{p} 53$ protein and DNA content are important biologic prognostic factors for thyroid cancer. Surgery 1996;119:568-75.

16. Cox DR. Regression models and life tables. J R Stat Soc B 1972;24:187-220.

17. Ishihara T, Yamazaki S, Kobayashi K, Inoue H, Fukai S, Ito $\mathrm{K}$, et al. Resection of the trachea infiltrated by thyroid carcinoma. Ann Surg 1982;195:496-500.

18. Andersen PE, Kinsella J, Loree TR, Shaha AR, Shah JP. Differentiated carcinoma of the thyroid with extrathyroidal extension. Am J Surg 1995;170:467-70.
19. Nakao K, Hamaji $M$, Nakahara $M$, Nishida $T$, Miyata $M$. Aggressive surgical approach to thyroid cancer with invasion of the trachea. Asian J Surg 1994;17:102-7.

20. Friedman M. Surgical management of thyroid carcinoma with laryngotracheal invasion. Otolaryngol Clin North Am 1990;23:495-507.

21. Sugenoya A, Matsuo K, Asanuma $\mathrm{K}$, Shingu $\mathrm{K}$, Shimizu T, Masuda $\mathrm{H}$, et al. Management of tracheal wall resection for thyroid carcinoma by tracheocutaneous fenestration and delayed closure using auricular cartilage. Head Neck 1995; 17:339-42.

22. DeGroot LJ, Kaplan EL, McCormick M, Straüs FH. Natural history, treatment, and course of papillary thyroid carcinoma. J Clin Endocrinol Metab 1990;71:414-24. 